\title{
Production of a recombinant polyester-cleaving hydrolase from Thermobifida fusca in Escherichia coli
}

\author{
Karolin Dresler · Joop van den Heuvel • \\ Rolf-Joachim Müller · Wolf-Dieter Deckwer
}

Received: 10 May 2006/ Accepted: 15 May 2006/ Published online: 13 June 2006

(C) Springer-Verlag 2006

\begin{abstract}
The hydrolase (Thermobifida fusca hydrolase; TfH) from T. fusca was produced in Escherichia coli as fusion protein using the OmpA leader sequence and a His ${ }_{6}$ tag. Productivity could be raised more than 100-fold. Both batch and fed-batch cultivations yield comparable cell specific productivities whereas volumetric productivities differ largely. In the fed-batch cultivations final rTfH concentrations of $0.5 \mathrm{~g} \mathrm{~L}^{-1}$ could be achieved. In batch cultivations the generated $\mathrm{rTfH}$ is translocated to the periplasm wherefrom it is completely released into the extracellular medium. In fed-batch runs most of the produced rTfH remains as soluble protein in the cytoplasm and only a fraction of about $35 \%$ is translocated to the periplasm. Migration of periplasmic proteins in the medium is obviously coupled with growth rate and this final transport step possibly plays an important role in product localization and efficacy of the Sec translocation process.
\end{abstract}

Keywords Recombinant protein expression . Batch culture $\cdot$ Fed-batch culture $\cdot$ Sec pathway Purification

\footnotetext{
K. Dresler · R.-J. Müller · W.-D. Deckwer $(\bowtie)$

Biochemical Engineering Group TU-BCE,

GBF Braunschweig, Gesellschaft für Biotechnologische

Forschung, Mascheroder Weg 1,

38124 Braunschweig, Germany

e-mail:wdd@gbf.de

J. van den Heuvel

Department of Structural Biology, GBF Braunschweig,

Gesellschaft für Biotechnologische Forschung,

Mascheroder Weg 1, 38124 Braunschweig, Germany
}

\author{
Abbreviations \\ CV Column volume \\ DCW Dry cell weight $\left(\mathrm{g} \mathrm{L}^{-1}\right)$ \\ DBP Dipeptide binding protein \\ EF Extracellular fraction \\ $F_{\text {glc }} \quad$ Volumetric feed rate $\left(\mathrm{L} \mathrm{h}^{-1}\right)$ \\ HCDC High cell density cultivation \\ iCF Insoluble cytoplasmic fraction \\ OD Optical density \\ OmpA Outer membrane protein A \\ $\mathrm{PF} \quad$ Periplasmic fraction \\ $p \mathrm{O}_{2} \quad$ Dissolved oxygen \\ $q_{\mathrm{p}} \quad$ Specific productivity [U $\left(\mathrm{g}_{\mathrm{DCW}} \mathrm{h}\right)^{-1}$ ] \\ $Q_{\mathrm{p}} \quad$ Volumetric productivity [U $(\mathrm{L} \mathrm{h})^{-1}$ ] \\ RQ Respiration quotient \\ rTfH Recombinant Thermobifida fusca hydrolase \\ $S \quad$ Glucose concentration in the feed $\left(\mathrm{g} \mathrm{L}^{-1}\right)$ \\ sCF Soluble cytoplasmic fraction \\ $t_{\mathrm{f}} \quad$ Time after feed start (h) \\ TfH Thermobifida fusca hydrolase \\ $(\mathrm{XV})_{0} \quad$ Biomass $(\mathrm{g})$ \\ $\mu_{\text {set }} \quad$ Specific growth rate $\left(\mathrm{h}^{-1}\right)$ \\ $Y_{\mathrm{X} / \mathrm{S}} \quad$ Biomass yield coefficient $\left(\mathrm{g} \mathrm{g}^{-1}\right)$
}

\section{Introduction}

Since more than 15 years, the interest in biodegradable plastics (polymeric materials which can be cleaved by enzymes and assimilated by microorganisms, respectively) is steadily raising and nowadays a number of commercial products are on the market. Polymers 
containing ester groups, especially polyesters, play a central role as they are easily subject to microbial attack, the degradation rate being largely dependent on their physical structure and chemical composition. First attempts to produce biodegradable plastics were based on natural polymers like poly( $\beta$-hydroxybutyrate) (PHB). However, their material properties proved to be insufficient and could not compete with those of synthetic polyesters. Tokiwa and Suzuki [1] already showed that also synthetic aliphatic polyesters are accessible to a biological degradation. However, aliphatic polyesters exhibit similar disadvantages concerning their material properties (e.g. minor tensile strength, low melting points) and therefore are hardly applicable for every day life products. On the other hand, polyesters such as poly(ethylene-terephthalate) (PET) and poly(butylene-terephthalate) (PBT) exhibit excellent material properties, but were classified as non-biodegradable. Therefore, aliphatic-aromatic copolyesters, which combine both acceptable use properties and sufficient biodegradability [2] were developed. The material properties desired for specific applications can be easily adjusted by the ratio of the aliphatic to the aromatic diacid [3, 4]. Commercial products are available now under the trade name Ecoflex $^{\circledR}$ (BASF AG, Germany).

Recently, a thermophilic actinomycete was isolated and identified as Thermobifida fusca (former name: Thermomonospora fusca) exhibiting a remarkable degradation capability for aliphatic-aromatic copolyesters [5, 6]. The extracellular hydrolase (TfH) responsible for the degradation of these copolyesters was purified from the culture broth and classified as a serine hydrolase with the highly conserved G-H-S-M$\mathrm{G}$ motif [7]. The mature hydrolase consists of 261 amino acids, corresponding to a molecular weight of $28.2 \mathrm{kDa}$. Maximum activity was found at $65-70^{\circ} \mathrm{C}$. The extracellular hydrolase gene was located on an operon containing two nearly identical genes (btal and bta2) with an amino acid identity of $92 \%$ [6].

The enzyme is only expressed by $T$. fusca if a polyester, such as poly(1,4-butandiole adipate-co-1,4butandiole terephthalate) (BTA) or poly ( $\epsilon$-caprolactone) (PCL) is present in the medium. Gouda et al. [8] observed, that the amount of enzyme excreted in the medium correlates with the amount of polyester added to the culture. This induction behaviour as well as adsorption and inhibition phenomena [8] complicate a large-scale production of this enzyme (TfH) and therefore, a simpler to handle recombinant expression system for producing $\mathrm{TfH}$, independent of the presence of the polymer was highly desirable, particularly, as recent investigations showed that TfH is capable of degrading even PET [9].

In this paper, we report on the heterologous expression of the polyester-degrading hydrolase from $T$. fusca in E. coli TG1. To this end, the TfH-encoding gene (btal) was cloned together with a C-terminal His $_{6}$-affinity tag and the ompA-secretion signal under the control of a thermo-inducible promoter. This strategy should enable translocation of the gene product by the Sec-transport system from the cytoplasm into the periplasmic space, where the properly folded $\mathrm{TfH}$ should accumulate after cleavage of the OmpA sequence. Several cultivation strategies and purification routes were considered. The aim of the investigations was to provide sufficient amounts of $\mathrm{TfH}$ for larger-scale polyester degradation studies (low purification grade) and a highly purified $\mathrm{TfH}$ for mechanistic studies and structural analysis.

\section{Materials and methods}

Cloning of the recombinant His $_{6}$-tagged TfH

Escherichia coli TG1 (DSM 6056) was used for the production of the recombinant hydrolase from Thermobifida fusca (rTfH). TG1 is characterized by the following genetic markers: supE $h s d \Delta 5$ thi $\Delta$ (lac-proAB) $\mathrm{F}$ [traD36 proAB ${ }^{+}$lacI $^{q}$ lacZ $\left.\Delta \mathrm{M} 15\right]$ [10].

The vector pCytexP1-OmpA-bta1 [6] was digested with $N d e$ I and EcoRI to obtain a DNA fragment consisting of $876 \mathrm{bp}$. This DNA fragment was used as a template to clone a $\mathrm{His}_{6}$ tag at the $\mathrm{C}$-terminal end using the primer set bta1-rev (5'-TAC TTA GGA TCC TTA TCA GTG GTG GTG GTG GTG GTG CTC GAG GAA CGG GCA GGT GGA GCG-3') and bta1-for (5'-GTC ATG GGC CAC TCC ATG GGC-3'). The DNA fragment was amplified using VENT DNA polymerase (New England Biolabs, USA), the cycle programme was run at $95^{\circ} \mathrm{C}$ for $2 \mathrm{~min}, 30$ cycles of $30 \mathrm{~s}$ at $95^{\circ} \mathrm{C}, 30 \mathrm{~s}$ at $50^{\circ} \mathrm{C}$ and $2 \mathrm{~min}$ at $55^{\circ} \mathrm{C}$, followed by an extension reaction for $5 \mathrm{~min}$ at $55^{\circ} \mathrm{C}$. The reaction mixture was designed according to the description of the manufacturer. The resulting PCR-fragment $r b t a 1-\mathrm{His}_{6}$ was purified using the JETQUICK PCR Fragment purification kit (GENOMED GmbH, Germany). rbta1-His ${ }_{6}$ was ligated to a DNA fragment obtained from the digestion of the origin vector with $N c o$ I and BamHI. The resulting plasmid pCYTEXP1-OmpA-btal-His ${ }_{6}$ with the secretion signal of OmpA, the hydrolase from $T$. fusca (TfH) and the affinity tag was used for the expression of rTfH. 
Transformation of pCYTEXP1-OmpA-btal-His 6 into E. coli TG1 was done by electroporation. Expression of the recombinant TfH (rTfH) was controlled by the strong tandem promoter $\lambda \mathrm{p}_{\mathrm{R}} \mathrm{p}_{\mathrm{L}}$, which is expressed by the thermolabile repressor cI857.

\section{Media}

Louria-Bertani medium (LB medium): $10 \mathrm{~g} \mathrm{~L}^{-1}$ tryptone, $10 \mathrm{~g} \mathrm{~L}^{-1} \mathrm{NaCl} 5 \mathrm{~g} \mathrm{~L}^{-1}$, yeast extract and $0.8 \mathrm{~g} \mathrm{~L}^{-1}$ glucose was used for cultivations of E. coli TG1 in the complex medium [11]. The medium was autoclaved at $121^{\circ} \mathrm{C}$ for $20 \mathrm{~min}$. Before cultivation, ampicillin $\left(100 \mu \mathrm{g} \mathrm{m}^{-1}\right)$ was added.

A defined medium as described by Korz et al. [12] was used for batch and fed-batch cultivation of $E$. coli TG1. The medium contained (per litre): $\left(\mathrm{NH}_{4}\right)_{2} \mathrm{PO}_{4} 4 \mathrm{~g}, \mathrm{KH}_{2} \mathrm{PO}_{4} 13.3 \mathrm{~g}$, citric acid $1.7 \mathrm{~g}$, glucose $25 \mathrm{~g}, \quad \mathrm{MgSO}_{4} \quad 1.2 \mathrm{~g}$, trace elements (Fe(III)citrate $\cdot \mathrm{H}_{2} \mathrm{O} \quad 100 \mathrm{mg}, \quad \mathrm{CoCl}_{2} \cdot 6 \mathrm{H}_{2} \mathrm{O} \quad 2.5 \mathrm{mg}$, $\mathrm{MnCl}_{2} \cdot 4 \mathrm{H}_{2} \mathrm{O} \quad 15 \mathrm{mg}, \quad \mathrm{CuCl}_{2} \cdot 2 \mathrm{H}_{2} \mathrm{O} 1.5 \mathrm{mg}, \mathrm{H}_{3} \mathrm{BO}_{3}$ $3 \mathrm{mg}, \mathrm{Na}_{2} \mathrm{MoO}_{4} \cdot 2 \mathrm{H}_{2} \mathrm{O} 2.5 \mathrm{mg}, \mathrm{Zn}\left(\mathrm{CH}_{3} \mathrm{COO}\right)_{2} \cdot 2 \mathrm{H}_{2} \mathrm{O}$ $13 \mathrm{mg}$, EDTA $8.4 \mathrm{mg}$ ) and $100 \mu \mathrm{L}$ antifoam (Sigma Antifoam 204, Sigma-Aldrich, USA). $\mathrm{MgSO}_{4}$ and glucose solution were autoclaved separately from the phosphate buffer and trace elements at $121^{\circ} \mathrm{C}$ for 20 min. $\mathrm{pH}$ was adjusted to 6.8 with $5 \mathrm{M} \mathrm{NaOH}$, before. Ampicillin $100 \mathrm{mg} \mathrm{L}^{-1}$ and thiamine hydrochloride $4.5 \mathrm{mg} \mathrm{L}^{-1}$ were sterilized by filtration (Sterivex, cut off of $0.2 \mu \mathrm{m}$, Millipore, USA) and added before starting the cultivation.

The feed solution for fed-batch cultivations contained the following components (in $1 \mathrm{~L}$ demineralized water): glucose $300 \mathrm{~g}, \mathrm{MgSO}_{4} 7.6 \mathrm{~g}$, trace elements (Fe(III)citrate $\cdot \mathrm{H}_{2} \mathrm{O} \quad 16.2 \mathrm{mg}, \quad \mathrm{CoCl}_{2} \cdot 6 \mathrm{H}_{2} \mathrm{O} \quad 1.5 \mathrm{mg}$, $\mathrm{MnCl}_{2} \cdot 4 \mathrm{H}_{2} \mathrm{O} \quad 8.9 \mathrm{mg}, \mathrm{CuCl}_{2} \cdot 2 \mathrm{H}_{2} \mathrm{O} \quad 0.9 \mathrm{mg}, \mathrm{H}_{3} \mathrm{BO}_{3}$ $1.9 \mathrm{mg}, \mathrm{Na}_{2} \mathrm{MoO}_{4} \cdot 2 \mathrm{H}_{2} \mathrm{O} 1.5 \mathrm{mg}, \mathrm{Zn}\left(\mathrm{CH}_{3} \mathrm{COO}\right)_{2} \cdot 2 \mathrm{H}_{2} \mathrm{O}$ $6.1 \mathrm{mg}$, EDTA $4.9 \mathrm{mg}$ ), thiamine hydrochloride $4.5 \mathrm{mg}$ and ampicillin $100 \mathrm{mg}$. The feed solution was sterilized by filtration.

\section{Cultivation}

A bioreactor (Biostat B2, B. Braun, Melsungen, Germany) with $2 \mathrm{~L}$ working volume connected to an exhaust gas analysis unit (S710, Sick Maihak, Germany) was used for the cultivations. Bioreactor control was done by a computer, operating the MFCS software (B. Braun). Feed and base reservoirs were stored on scales connected to the computer. Starting conditions of the reactor were set to $30^{\circ} \mathrm{C}, 500 \mathrm{rpm}, \mathrm{pH}$ 6.8 and $1 \mathrm{~L} \mathrm{~min}^{-1}$ airflow. $\mathrm{pH}$ was controlled by adding either $25 \% \mathrm{NH}_{3}$ (in case of the complex medium: $5 \mathrm{M}$
$\mathrm{NaOH}$ ) or $1 \mathrm{M} \mathrm{H}_{3} \mathrm{PO}_{4}$. The minimum level of dissolved oxygen $\left(\mathrm{pO}_{2}\right)$ was set to $20 \%$ and was adjusted automatically by the stirrer speed and aeration rate. If the stirrer speed and aeration rate run at maximum, pure $\mathrm{O}_{2}$ had to be enriched to the inlet airflow. Antifoam was added manually to the cultivation under sterile conditions, if necessary.

Pre-cultures were carried out in the respective medium of the main culture by inoculation with a glycerol stock of E. coli TG1 containing the plasmid pCYTEXP1-OmpA-bta1-His ${ }_{6}$ at $30^{\circ} \mathrm{C}$ and $180 \mathrm{rpm}$ for $12 \mathrm{~h}$. Batch and fed-batch cultivation in the bioreactor was started by adding $20 \mathrm{~mL}$ of preculture.

In batch cultivation, induction of rTfH production was started at an OD of $0.5-0.6$ by raising the cultivation temperature from 30 to $39^{\circ} \mathrm{C}$ or $42^{\circ} \mathrm{C}$, respectively, within about 15 min.

In the fed-batch cultivation, feed was started after the initial glucose was consumed as indicated by a sharp increase in $p \mathrm{O}_{2}$. An exponential feed profile was used. For a desired specific growth rate $\mu_{\text {set }}\left(\mathrm{h}^{-1}\right)$, the volumetric feed rate $F_{\text {glc }}\left(\mathrm{L} \mathrm{h}^{-1}\right)$ was calculated from (Eq. 1) [13]:

$F_{\text {glc }}=\frac{\mu_{\text {set }}(X V)_{0} \mathrm{e}^{\mu_{\text {set }} t_{\mathrm{f}}}}{Y_{\mathrm{X} / \mathrm{S}} S}$

where $(X V)_{0}$ is the biomass $(\mathrm{g})$ at feed start, $t_{\mathrm{f}}$ the time $(\mathrm{h})$ after feed start, $Y_{\mathrm{X} / \mathrm{S}}$ the biomass yield coefficient $\left(0.4 \mathrm{~g} \mathrm{~g}^{-1}\right)$ and $S$ the glucose concentration in the feed $\left(\mathrm{g} \mathrm{L}^{-1}\right)$. Substrate consumption by maintenance is not considered in Eq. 1. Therefore, the actual growth rate may be less than the set value $\left(\mu_{\text {set }}=0.12 \mathrm{~h}^{-1}\right)$. Feed rate and volume variations were corrected automatically by the MFCS software. The expression of rTfH was initiated at a biomass level of about $40 \mathrm{~g} \mathrm{~L}^{-1}$ by shifting the temperature to $39^{\circ} \mathrm{C}$, which was found optimal in the preliminary runs. After induction, the feed-rate profiles were kept constant at the value of the induction time or it was continously increased as given by Eq. 1 for $\mu_{\text {set }}=0.12 \mathrm{~h}^{-1}$.

Analytical methods

Cell-mass concentration was followed by OD at $600 \mathrm{~nm}$ (Ultrospec 3100 pro, Amersham Biosciences, Sweden). For the determination of the dry cell weight (DCW), $1 \mathrm{~mL}$ of the culture was added in triplicate to pre-weighed tubes and centrifuged for $5 \mathrm{~min}$ at $13,000 \mathrm{~g}$ and $4^{\circ} \mathrm{C}$. After a subsequent washing step, the pellet was dried until constant mass at $45^{\circ} \mathrm{C}$ under vacuum. 
Extracellular glucose and metabolites such as acetate, formate, succinate, propionate and isobutyrate were determined in the supernatant. To this end, the supernatant was heated up to $80^{\circ} \mathrm{C}$ for $5 \mathrm{~min}$ and centrifuged $\left(13,000 \mathrm{~g}, 10 \mathrm{~min}, 4^{\circ} \mathrm{C}\right)$ to eliminate the precipitated proteins. The supernatant was additionally filtered (pore size $0.2 \mu \mathrm{m}$ ) before applied into the HPLC (Shimadzu, Japan) using an Aminex HPX-87H column (Biorad, USA). $5 \mathrm{mM} \mathrm{H}_{2} \mathrm{SO}_{4}$ with a flow rate of $0.6 \mathrm{~mL} \mathrm{m^{-1 }}$ was used as mobile phase at a temperature of $60^{\circ} \mathrm{C}$.

\section{Electrophoresis}

SDS-PAGE was performed with a Mini Protean ${ }^{\circledR} 3$ apparatus (Bio-Rad, USA) according to the manufacturer's recommendations. The samples were run on $12 \%$ polyacrylamide gel. Molecular mass marker was purchased from Bio-Rad. Proteins were stained with Comassie-Blue [11] or silver [14].

Proteins were transferred onto a $0.45-\mu \mathrm{m}$ PVDF membrane (Immobilon ${ }^{\mathrm{TM}}-\mathrm{P}$ Transfer Membrane, USA) using a Semi-Dry Transfer Unit (Semiphor ${ }^{\mathrm{TM}}$ Hoefer $\mathrm{TE}^{\circledR} 70$ Series, Amersham Bioscience, Sweden). rTfH was detected by Comassie-Blue staining.

\section{Hydrolase activity}

Hydrolase activity was measured by monitoring the cleavage of $p$-nitrophenylpalmitate ( $p$ NPP) as described by Schmidt-Dannert et al. [15]. The released $p$-nitrophenol was determined spectrophotometrically (Ultrospec 3100 pro, Amersham Biosciences, Sweden). $p$ NPP solution was freshly prepared by mixing $1 \mathrm{~mL} p \mathrm{NPP}$ dissolved in 2-propanol at a concentration of $3 \mathrm{~g} \mathrm{~L}^{-1}$

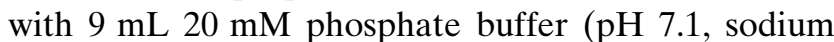
taurocholate $2.3 \mathrm{~g} \mathrm{~L}^{-1}$, gum arabic $\left.1.1 \mathrm{~g} \mathrm{~L}^{-1}\right)$. Immediately after addition of the enzyme sample the absorption was measured at $400 \mathrm{~nm}$ and $25^{\circ} \mathrm{C}$ against a sample without enzyme for $2 \mathrm{~min}$. One unit was defined as the amount of enzyme that caused the release of $1 \mu \mathrm{mol} p$-nitrophenol per minute under test conditions. The extinction coefficient of $p$-nitrophenol is $9.62 \mathrm{~cm}^{2} \mu \mathrm{mol}^{-1}$. To compare the photometrically determined $p$ NPP activity units with a previously used activity test [8] the cleavage of the polyester bonds of PCL (poly( $\epsilon$-caprolactone)) films in a pHstat titration system was additionally measured as described by Gouda et al. [8]. It was found that one $p$ NPP enzyme unit corresponds to three PCL units.

\section{Localization of rTfH}

In this paper, it is discriminated among the various rTfH fractions located in the extracellular medium, the periplasmic space and the cytoplasm as soluble or insoluble protein. The extracellular fraction (EF) was obtained from the culture supernatant after centrifugation $\left(13,000 \mathrm{~g}, 5 \mathrm{~min}, 4^{\circ} \mathrm{C}\right)$. A variation of the protocol of Neu et al. [16] was used to obtain the periplasmic fraction (PF). Biomass (about $37 \mathrm{mg}$ ) corresponding to ten OD was resuspended in $1 \mathrm{~mL}$ ice-cold $30 \mathrm{mM}$ Tris- $\mathrm{HCl}(\mathrm{pH}$ 8.0) containing $20 \%$ sucrose and $1 \mathrm{mM}$ EDTA and after incubation for $10 \mathrm{~min}$ at room temperature centrifuged at $13,000 \mathrm{~g}$ and $4^{\circ} \mathrm{C}$ for $10 \mathrm{~min}$. The supernatant was separated from the cell pellet and stored at an ice bath. The cell pellet was again resuspended in $1 \mathrm{~mL}$ ice-cold $5 \mathrm{mM} \mathrm{MgSO}_{4}$ solution and was slightly rotated on ice for $10 \mathrm{~min}$. After centrifugation the supernatant was pooled with the previously obtained supernatant giving the total periplasmic proteins (PF). Each fraction (EF and $\mathrm{PF}$ ) was stored at $-20^{\circ} \mathrm{C}$ until further use.

Soluble proteins harboured in the cytoplasm were obtained by resuspending the cells in $275 \mu \mathrm{L}$ PBS buffer [11] [pH 7.2, 10\% (v/v) BugBuster, 0.1\% (v/v) benzonase (both Novagen, USA), $275 \mathrm{U}$ lysozyme], slightly rotated at room temperature for $20 \mathrm{~min}$ and centrifuged at $13,000 \mathrm{~g}$ and $4^{\circ} \mathrm{C}$ for $25 \mathrm{~min}$. The supernatant formed the soluble cytoplasmic fraction $(\mathrm{sCF})$. To gain the insoluble cytoplasmic protein fraction (iCF) cells were again resuspended in PBS buffer (10\% (v/v) BugBuster, 27.5 U lysozyme) and after incubation for 5 min diluted sixfold with PBS buffer (1\% (v/v) BugBuster). After centrifugation at $5,000 \mathrm{~g}$ and $4^{\circ} \mathrm{C}$ for 15 min cells were washed twice with $800 \mu \mathrm{L}$ PBS (1\% (v/v) BugBuster). Final centrifugation was done at $13,000 \mathrm{~g}$ and $4^{\circ} \mathrm{C}$ for $25 \mathrm{~min}$. The pellet was then resuspended in $275 \mu \mathrm{L}$ of $1 \%(\mathrm{w} / \mathrm{v})$ SDS.

\section{Purification of rTfH}

To gain a rTfH solution of low purification grade $75 \mathrm{mg}$ biomass was resuspended in $2 \mathrm{~mL}$ ice-cold PBS buffer, pH 7.2 [11]. Cells were disrupted by ultrasonification (Sonopuls HD 2070, Sonotrode UW 2070, Bandelin electronics, Germany) in an ice bath using three intervals each of $30 \mathrm{~s}$ pulse and $2 \mathrm{~min}$ break. Subsequently, disrupted cell were denaturated by heat at $55^{\circ} \mathrm{C}$ for $10 \mathrm{~min}$, and centrifuged $(13,000 \mathrm{~g}$, $\left.25 \mathrm{~min}, 4^{\circ} \mathrm{C}\right)$. The supernatant was stored at $-20^{\circ} \mathrm{C}$.

Highly purified rTfH was recovered from the extracellular and the PF (see Localization of rTfH 
section). Chelating Sepharose ${ }^{\mathrm{TM}}$ Fast Flow Gel (Amersham Bioscience) was activated as described by the manufacturer and added to the solution harbouring $\mathrm{rTfH}(1 \mathrm{~mL}$ chromatographic material was used for $400 \mathrm{U})$. The suspension was stirred for $1 \mathrm{~h}$ and filled then into a XK 26/60-column (AmershamBioscience) and after the chromatographic material has settled, the column was connected to the FPLC system (LCC-500 Plus, Amersham Bioscience, Sweden). Column was washed with 3 column volumes $(\mathrm{CV})$ binding buffer containing $20 \mathrm{mM}$ Tris (pH 7.5), $500 \mathrm{mM} \mathrm{NaCl}$ and $10 \mathrm{mM}$ imidazole at a flow rate of $4 \mathrm{~mL} \mathrm{~min}^{-1}$. Elution of the bound $\mathrm{rTfH}$ was done by a linear increase of the imidazole concentration to $500 \mathrm{mM}$ within $3 \mathrm{CV}$. Fractions with activity were pooled and concentrated by ultrafiltration (Amicon Stirred Cell 1050 or 1010, Amicon, USA) using a regenerated cellulose membrane (YM Ultrafiltration Membranes, cut off: $10 \mathrm{kDa}$, Amicon, USA). $6 \pm 0.5 \mathrm{~mL}$ of the concentrated enzyme was applied manually to the gel filtration column (HiLoad 26/60 Superdex 75 prep grade, Amersham Bioscience) equilibrated with $0.9 \% \mathrm{NaCl}$. The flow rate was set to $2 \mathrm{~mL} \mathrm{~min}^{-1}$ to elute the proteins. Fractions with activity were pooled and stored at $-20^{\circ} \mathrm{C}$ until further use. Whenever necessary, rTfH solution was concentrated by ultrafiltration.

\section{Protein determination}

Protein was determined by Roti ${ }^{\circledR}$-Nanoquant (Roth, Germany) as described by the manufacturer.

\section{Results}

Batch cultivations

E. coli TG1 harbouring the plasmid pCYTEXP1OmpA-bta1-His 6 was firstly cultivated batchwise with complex medium in $1 \mathrm{~L}$ scale monitoring OD, DCW, glucose and metabolites in the supernatant. At an OD of about 0.6 , cultivation temperature was raised to either 39 or $42^{\circ} \mathrm{C}$ to induce $\mathrm{rTfH}$ production. After starting induction, generation of rTfH was pursued by the spectrophotometric assay in the extracellular and PFs. Results are shown in Fig. 1.

Glucose present in the complex medium is quickly consumed at about 1.4-2 h after induction (Fig. 1c). Consumption of glucose is accompanied by formation of acetate, its extracellular concentration peaks at $39^{\circ} \mathrm{C}$ at $2 \mathrm{~h}\left(3 \mathrm{~h}\right.$ at $42^{\circ} \mathrm{C}$, respectively), which is remetabolized after total glucose consumption. The consump- tion pattern is reflected by biomass development and $\mathrm{CO}_{2}$ generation (Fig. 1a) which show a two- and threephase behaviour, respectively. Firstly growth rate is highest as long as glucose is available (induction at $39^{\circ} \mathrm{C}$ ). The following consumption of the intermediate acetate leads to reduced growth rate. After acetate consumption the growth rate further declines and finally growth ceases, however, $\mathrm{CO}_{2}$ evolution is yet observed in the stationary phase. From the biomass and $\mathrm{CO}_{2}$ evolution, one has to conclude that in all cultivation phases considerable amounts of constituents of the complex fractions of the medium are also consumed. For instance, the $1.5 \mathrm{~g} \mathrm{~L}^{-1}$ biomass $(2 \mathrm{~h}$ after induction at $39^{\circ} \mathrm{C}$ ) cannot be generated alone by glucose consumption. Unfortunately, the complex constituents are not known. Therefore, a carbon balance is not possible.

The production of the hydrolase $\mathrm{rTfH}$ is shown in Fig. 1b. Both induction profiles, shifting the temperature to 39 or $42^{\circ} \mathrm{C}$, revealed similar rTfH production kinetics. Shortly after induction $\mathrm{rTfH}$ is only found in the periplasm. However, in the course of the cultivation, rTfH did not accumulate in the PF as expected due to the leader signal OmpA. Surprisingly rTFH was entirely found in the extracellular medium at the end of the cultivation. At an induction of $42^{\circ} \mathrm{C}$ the promoter $\lambda \mathrm{p}_{\mathrm{R}} \mathrm{p}_{\mathrm{L}}$ in front of the bta1 gene is stronger than at $39^{\circ} \mathrm{C}$, but expression of rTfH is nearly finished about $6 \mathrm{~h}$ after induction resulting in a lower volumetric activity (only $60 \%$ ). About $4 \mathrm{~h}$ after induction, a remarkable increase of extracellular $\mathrm{rTfH}$ activity was observed which obviously correlates with a high metabolic activity as indicated by the second strong increase in $\mathrm{CO}_{2}$ evolution. The rise in $\mathrm{rTfH}$ activity cannot solely originate from translocation but suggest additional secretion from cytoplasm. Apparently expression of rTfH is faster than its transport through the cytoplasmic membrane in the early phase shortly after induction. In shake-flask cultivation, the rTfH production was monitored in the cytoplasm as soluble and insoluble cytoplasmic fractions (iCFs; data not shown). Maximum hydrolase activity was achieved after about $7.5 \mathrm{~h}$ summing up all compartments. Subsequently, the total hydrolase activity was slightly decreased, and finally rTfH was only detected in the supernatant.

To study the influence of medium composition on recombinant $\mathrm{TfH}$ production and to follow the transport of the enzyme into the medium, batch cultivations with the defined medium containing $23 \mathrm{~g} \mathrm{~L}^{-1}$ glucose were carried out (Fig. 2). rTfH was again induced at low OD. The course of the cultivation with the defined medium is remarkably different from that using the 


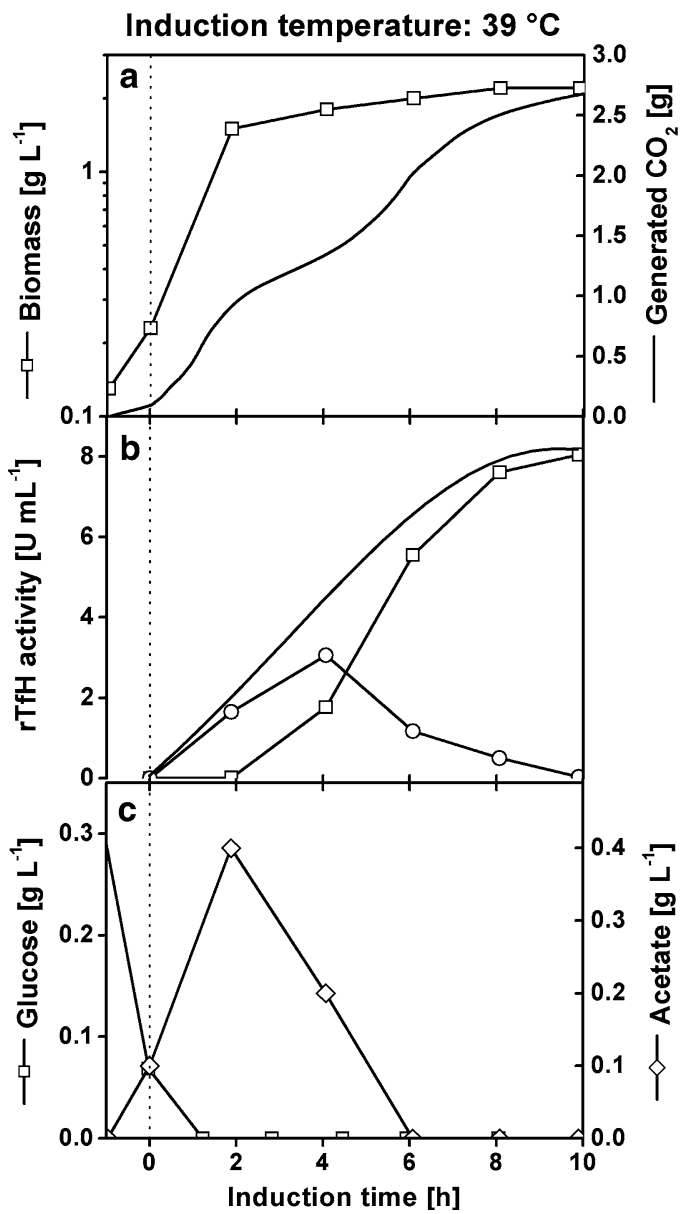

Fig. 1 Expression of rTfH in E. coli TG1 during batch cultivation with LB medium. Cells grew at $30^{\circ} \mathrm{C}$ to an $\mathrm{OD}$ of 0.6 before starting induction by a temperature shift to 39 or $42^{\circ} \mathrm{C}$, a growth and $\mathrm{CO}_{2}$ generation, b rTfH activity in different

complex medium. Raising the temperature to either $39^{\circ} \mathrm{C}$ or $42^{\circ} \mathrm{C}$ caused firstly a low growth rate. The consumption of glucose was coupled with acetate formation; $8 \mathrm{~h}$ after induction at $39^{\circ} \mathrm{C}$, growth rate rised to about $0.5 \mathrm{~h}^{-1}\left(0.6 \mathrm{~h}^{-1}\right.$ at an induction at $\left.42^{\circ} \mathrm{C}\right)$ and both glucose and acetate were consumed while a low amount of succinate was generated which was remetabolized after exhaustion of other C-substrates. As expected, growth was directly coupled with $\mathrm{CO}_{2}$ evolution. The respiration coefficient RQ was around 1 , the yield coefficient (biomass on glucose) was determined as $0.4 \mathrm{~g} \mathrm{~g}^{-1}$ for the batch cultivation at $39^{\circ} \mathrm{C}$. Over the entire induction period (about $23 \mathrm{~h}$ ), carbon balances of the cultivation with the defined medium were close to100 $\pm 3 \%$.

In contrast to the cultivation in LB medium, succinate was detected in the extracellular medium under both the induction profiles. Succinate is a typical product of the anaerobic metabolism of E. coli. It is

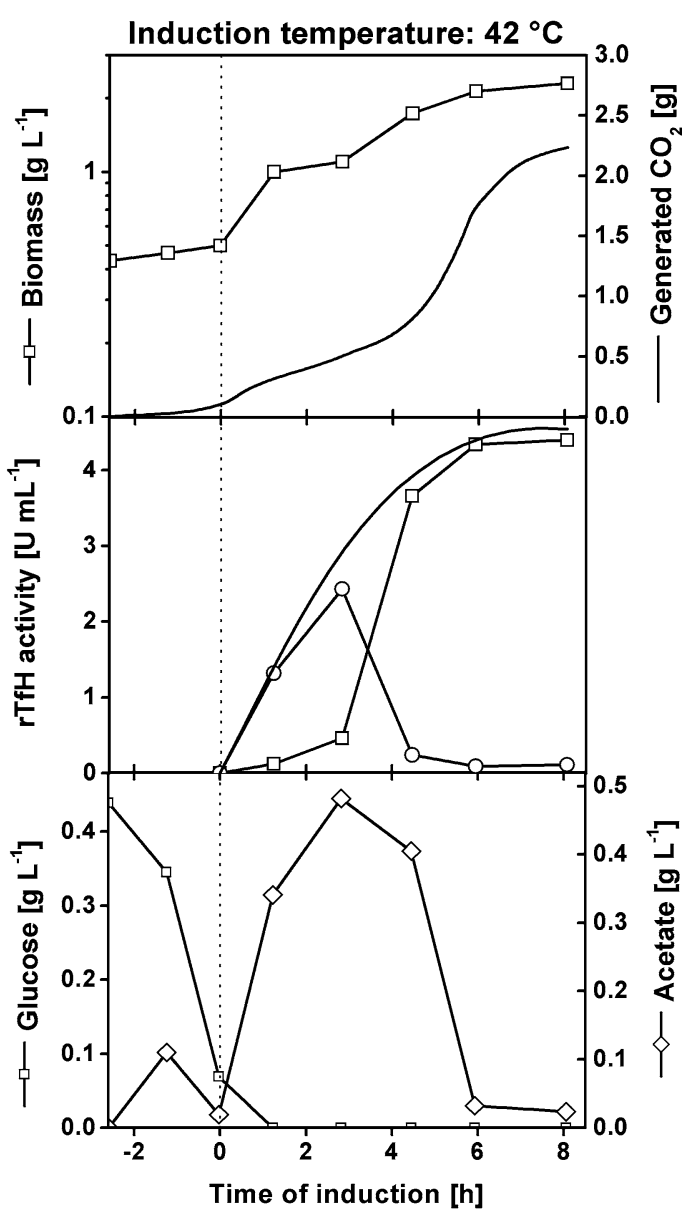

locations, extracellular fraction (EF; open square), periplasmic fraction (PF; open circle), sum of all fractions (continuous line), c glucose and acetate in broth

produced during the mixed acid fermentation and the fumarate reduction. Both pathways are strictly regulated by Fnr the global regulator of the anaerobic metabolism [17]. With the applied experimental approach, anaerobiosis can be excluded. The formation of succinate was coupled with the $\mathrm{CO}_{2}$ evolution and hence with a high metabolic activity. This may lead to an imbalance in the citric cycle or reduction equivalents. Unfortunately, other metabolites of the citric cycle were not determined in the supernatant supporting this assumption. Similar observations were made by Korz in batch cultivations using the same defined medium. He correlated the succinate formation with the amount of $\mathrm{CO}_{2}$ raising in the exhaust gas [18].

While secretion of rTfH in the periplasm started immediately after induction, the rate of $\mathrm{rTfH}$ release in the cultivation medium correlates with the growth rate, i.e., growth and product transport from the cytosol via 


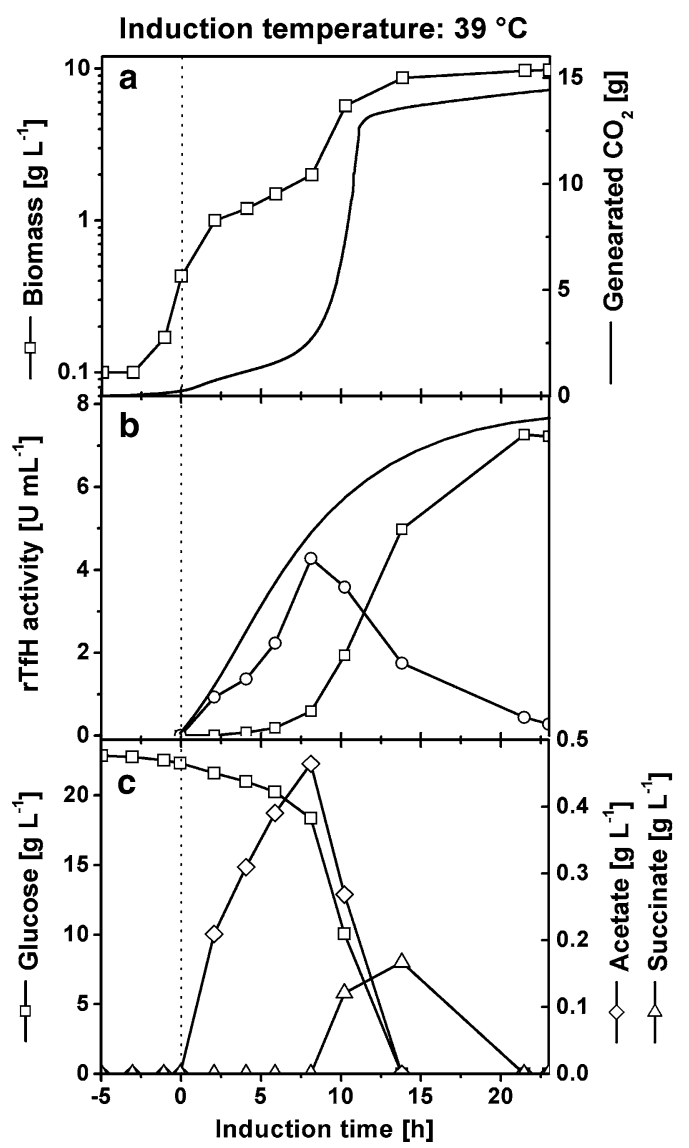

Fig. 2 Expression of rTfH in E. coli TG1 during batch cultivation with the defined medium. Cells grew at $30^{\circ} \mathrm{C}$ up to an OD of 0.6 before starting induction by a temperature shift to

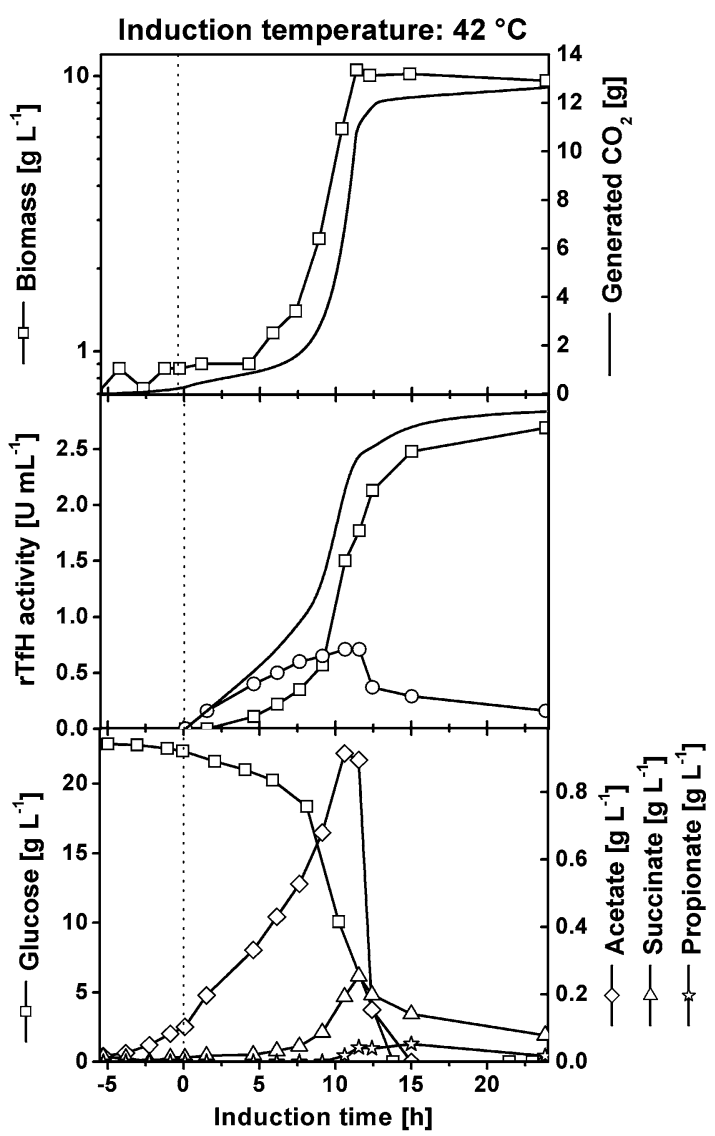

$39^{\circ} \mathrm{C}$ or $42^{\circ} \mathrm{C}$, a growth and $\mathrm{CO}_{2}$ generation, b rTfH activity in different locations, EF (open square), PF (open circle), sum of all fractions (continuous line), $\mathbf{c}$ glucose and metabolites in broth

$42^{\circ} \mathrm{C}$. While the volumetric activities achieved for the complex and the defined media at the same induction temperature are comparable, the specific activities differ significantly due to the higher biomass obtained with the defined medium. As the induction time is considerably longer for the cultivation in the defined medium, the specific productivities differ even more. These results clearly indicate that production of the rTfH in batch cultivation becomes more attractive when the complex medium is employed.

During the induction phase, the protein content in the culture supernatant was analysed by SDS-PAGE (Fig. 3). About $4 \mathrm{~h}$ after the temperature upshift, the first protein bands can be recognized, particularly, for the cultivation with LB medium, where rTfH and other protein bands appear simultaneously. In cultivations with the defined medium, the pattern looks differently. In the first phase, up to almost $4 \mathrm{~h}$ after induction, a single protein of about $57.4 \mathrm{kDa}$ is found. By N-terminal sequencing, this band could be identified as the periplasmic located dipeptide binding protein (DBP), which is involved in the transport of dipeptides [19]. In 


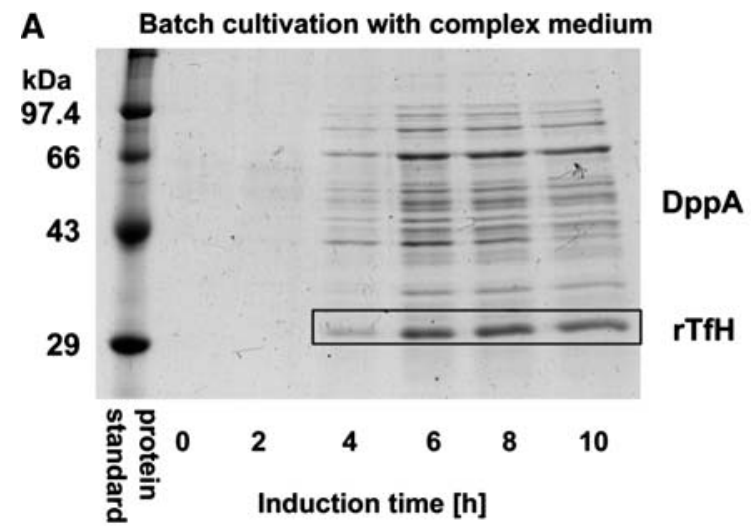

Fig. 3 SDS-PAGE under denaturating conditions: EFs of different cultivations are shown after increasing the temperature to $39^{\circ} \mathrm{C}$ to induce $\mathrm{rTfH}$ production, a batch cultivation with

the cultivation with complex medium, leakage of the outer membrane increased significantly $6 \mathrm{~h}$ after induction when $\mathrm{C}$-starvation began, growth was slow but $\mathrm{CO}_{2}$ generation was still high. With the defined medium protein release in the extracellular medium was drastically rising at about $12 \mathrm{~h}$ after induction when all glucose was consumed. The findings shown in Fig. 3 are in accordance with the results reported by Rinas and Hoffmann [20], who studied in detail the leakage of host-cell proteins of recombinant and nonrecombinant E. coli. These authors concluded that irrespective of the cell line, proteins of periplasmic origin are predominantly released in the medium, specifically, under stress conditions like temperature increase, nutrient starvation and high cell densities.

The SDS-PAGE shown in Fig. 3 indicates that the further protein bands observed for each media differ only in their intensity but not in their composition. This suggests that protein release in the medium cannot be attributed to cell lysis but is mainly due to an increasing leakage of proteins located and transported to the periplasm from the cytoplasm by the Sec-transport system.

This conclusion is also confirmed by analysis of the $\mathrm{N}$-terminal sequence of $\mathrm{rTfH}$, which clearly revealed that the OmpA leader sequence has been cleaved. However, cleavage was not uniform. Only $15 \%$ of the secreted $\mathrm{rTfH}$ found in the extracellular medium was cleaved at the expected cleavage site (Fig. 4). The

\section{MKKTAIAIAVALAGFATVAQAMANPYERGPNP

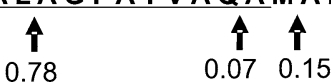

Fig. 4 Amino acid sequence of the signal peptide OmpA (underlined) and the beginning of $\mathrm{rTfH}$; arrows mark the cleavage site and their relative frequency

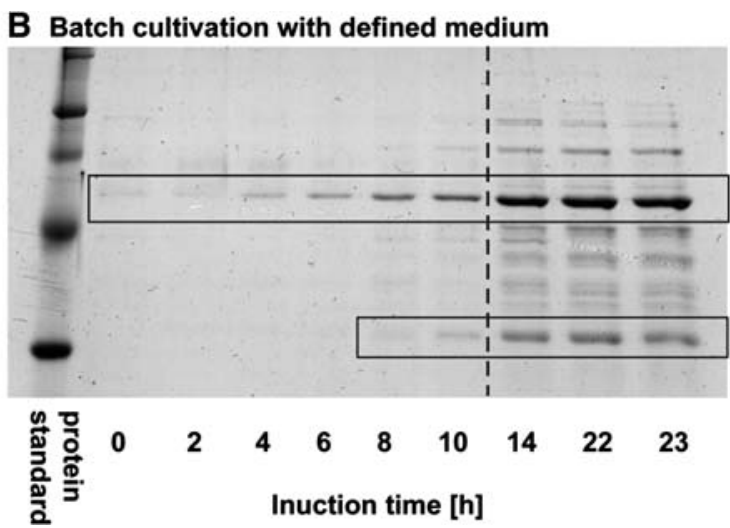

complex medium, b batch cultivation with the defined medium, dashed line marks the beginning of glucose starvation

remaining rTfH still carried parts of the OmpA leader peptide. The incomplete processing of signal sequences has been reported before [21]. The cleavage motif of a signal petidase is the A-X-A box [21] and fission occurs after the $X$. The N-terminal analysis of the secreted rTfH revealed that the cleavage motif is kept. These observations may allow the conclusion that the Sec-transportation pathway is overloaded, which might explain the improper cleavage of the signal peptidase.

\section{Fed-batch cultivation}

To enlarge volumetric rTfH activities, fed-batch cultivations were carried out. The basic assumption is that the volumetric productivity $Q_{\mathrm{p}}\left[\mathrm{U}(\mathrm{L} \mathrm{h})^{-1}\right]$ is given by equation

$Q_{\mathrm{p}}=q_{\mathrm{p}} X$

with the specific productivity $q_{\mathrm{p}}\left[\mathrm{U}\left(\mathrm{g}_{\mathrm{DCW}} \mathrm{h}\right)^{-1}\right]$, which is anticipated to be approximately constant when increasing the biomass concentration. As observed in the controlled batch cultivation it was also thought that the target enzyme may be released into the cultivations medium from the periplasmic space under high cell density conditions, thus facilitating down-stream processing [20]. High cell density cultivation (HCDC) for E. coli can be effectively performed by using an appropriate defined medium. After the batch phase with unlimited growth and consumption of glucose, the cultivation is continued by feeding glucose at a feed rate resulting in a reduced growth rate $\left(\mu_{\text {set }}<\mu_{\text {max }}\right.$; Eq. 1). Thus, oxygen starvation can be prevented and the culture grows under glucose limitation in the feed phase. The oxygen partial pressure was kept constant 

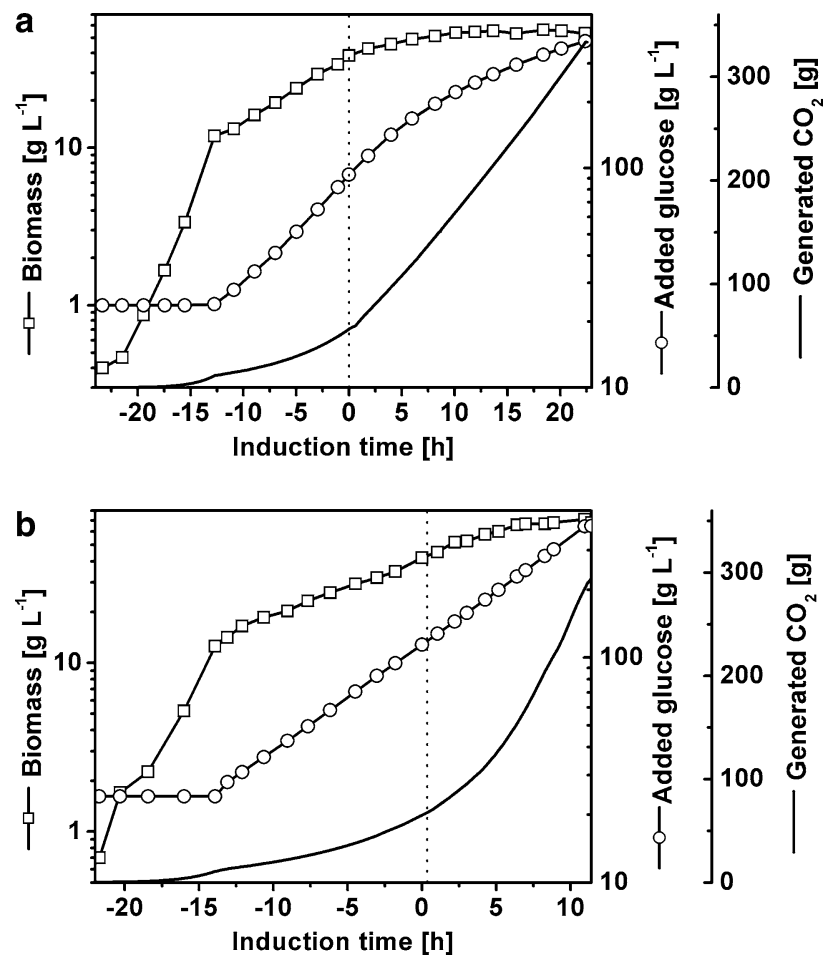

Fig. 5 Expression of rTfH in E. coli TG1 during HCDC. Cells grew at $30^{\circ} \mathrm{C}$ before induction by shifting the temperature to $39^{\circ} \mathrm{C}$ (dashed line). a After $12.8 \mathrm{~h}$, the batch phase ended and exponential feed was started and set to a growth rate $0.12 \mathrm{~h}^{-1}$. At the time point of $25.5 \mathrm{~h}$, feeding was set to a constant rate $\left(12.8 \mathrm{~g}_{\mathrm{glc}} \mathrm{h}^{-1}\right)$. b Fed batch with an exponential feeding profile with $\mu_{\text {set }}=0.12 \mathrm{~h}^{-1}$ over the entire feed phase including induction

at $20 \%$ as described in the Cultivation section. Two typical HCDC runs are shown in Fig. 5.

Starting with an initial glucose concentrations of $24 \mathrm{~g} \mathrm{~L}^{-1}$, the biomass concentration is about $12 \mathrm{~g}_{\mathrm{DCW} \mathrm{L}} \mathrm{L}^{-1}$ at the end of the batch phase (Fig. 5a, b). Due to the metabolic overflow, acetate was generated in the unlimited growth phase $\left(\mu_{\max }=0.47 \mathrm{~h}^{-1}\right)$, which was remetabolized at the end of the batch phase (Fig. 6). Then the glucose feed was started. The feed rate was adjusted to give a growth rate of about $0.12 \mathrm{~h}^{-1}$ according to Eq. 1, by assuming a yield coefficient $Y_{\mathrm{X} / \mathrm{S}}$ of $0.4 \mathrm{~g} \mathrm{~g}^{-1}$. The actually measured growth rates were 0.09 (Fig. 5a, b). In Run A, after a feed phase of $12.8 \mathrm{~h}$, a biomass concentration of $38.5 \mathrm{~g}_{\mathrm{DCW}} \mathrm{L}^{-1}$ was obtained and at this point, the expression of rTfH was induced by shifting the temperature from 30 to $39^{\circ} \mathrm{C}$ within $15 \mathrm{~min}$. The glucose feed rate was not further increased $\left(12.8 \mathrm{~g}_{\mathrm{glc}} \mathrm{h}^{-1}\right)$ but kept constant to the value when the induction was started. Therefore, the growth rate steadily decreased and after about $14 \mathrm{~h}$, the induction growth ceased. In the first phase after induction $(14 \mathrm{~h})$, an average growth rate of roughly $0.03 \mathrm{~h}^{-1}$ can be estimated from the data. However, over the entire period of $22.4 \mathrm{~h}$ with the constant feed rate, $\mathrm{CO}_{2}$-generation rate was also constant. Therefore, the fed glucose is used only for maintenance in the second part of the induction phase when there was zero growth . In the fed-batch phase of Run B, the same exponentially increasing glucose-feed rate as for Run A was applied, i.e., $F_{\text {glc }}$ was calculated from Eq. 1 for $\mu_{\text {set }}=0.12 \mathrm{~h}^{-1}$ and $Y_{\mathrm{X} / \mathrm{S}}=0.4 \mathrm{~g} \mathrm{~g}^{-1}$. After starting the induction at $42 \mathrm{~g} \mathrm{~L}^{-1}$, DCW exponential glucose feeding was continued for the same $\mu_{\text {set }}\left(0.12 \mathrm{~h}^{-1}\right)$. In spite of the exponential glucose feeding, growth decreased and ceased about $6 \mathrm{~h}$ after induction. An average growth of $0.07 \mathrm{~h}^{-1}$ can be estimated from the experimental biomass data at the first $6 \mathrm{~h}$ of the induction phase. $\mathrm{CO}_{2}$ generation increased exponentially even when the growth was negligible in the second half of the induction phase. After $11.4 \mathrm{~h}$ induction, a final biomass concentration of $67.8 \mathrm{~g}_{\mathrm{DCW}} \mathrm{L}^{-1}$ was obtained.

In the course of both runs, the respiratory quotient was always about $1( \pm 0.02)$. This indicates that consumed glucose was exclusively used for ATP production. Indeed, an intermediate formation of fermentative by-products such as acetate, succinate and formate was only observed at low level at the beginning and end of the induction period (Fig. 6). Both during the fed-batch and the induction phase, the glucose concentration was always zero. Carbon balances were checked by the installed computer program with consideration of volume changes by feeding and sampling and found to be close to100 $\pm 2 \%$.

The kinetics of the appearance of the heterologous gene product (rTfH) in the periplasm and cultivation broth is shown in Fig. 7 for Run A with a long induction phase $(>20 \mathrm{~h})$. The activity in the periplasm steadily increased up to a value above $70 \mathrm{U} \mathrm{mL}^{-1}$ while in the first $10 \mathrm{~h}$, no rTfH was released in the superna-

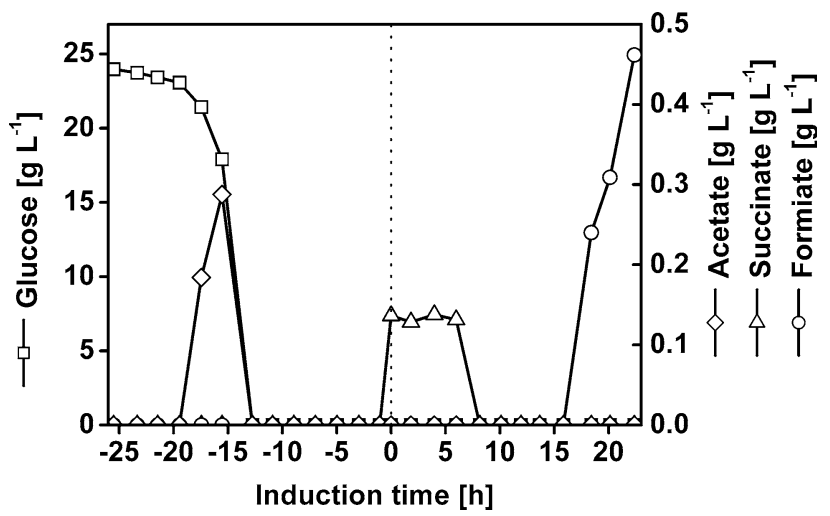

Fig. 6 Glucose and metabolites formed during HCDC (Run A). cf. Fig. 5 


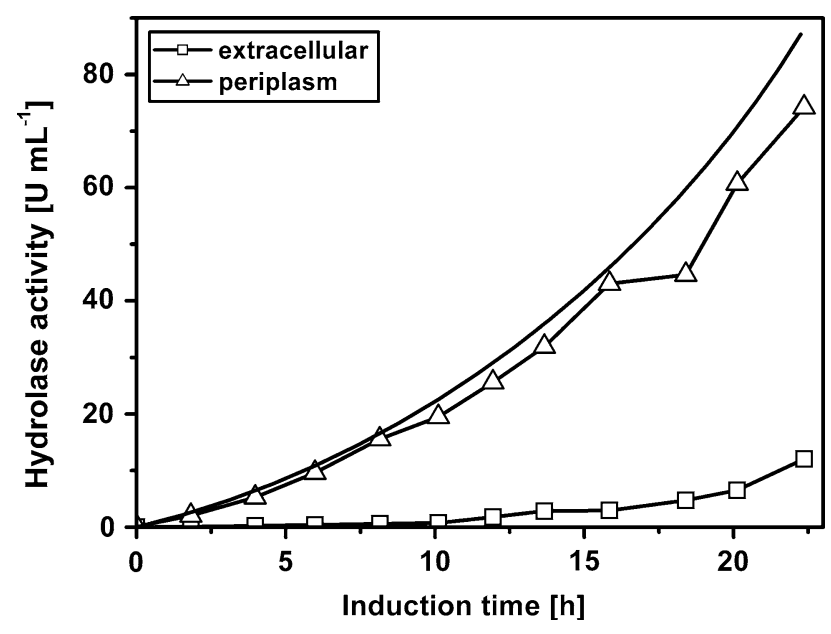

Fig. 7 Production kinetic of rTfH in the fed-batch cultivation (Run A). At a biomass of $38.5 \mathrm{~g}_{\mathrm{DCW}} \mathrm{L}^{-1} \mathrm{rTfH}$ expression was induced by raising the temperature to $39^{\circ} \mathrm{C}$

tant. The final activity in the medium was rather low $\left(12 \mathrm{U} \mathrm{mL}^{-1}\right)$. A similar release kinetics as shown in Fig. 7 was also observed for Run B, which differs largely from the behaviour found for batch cultures (Figs. 1, 2). In contrast to the batch cultivations the periplasmic activity does not pass a maximum and, particularly, little product (say less than $15 \%$ ) is found in the medium.

However, despite the low leakage of rTfH into the medium a SDS-PAGE (Fig. 8) made from the supernatant after the enzyme induction showed that the cells were already leaky at the beginning of the induction, which is proven by the appearance of the periplasmic DBP. During the induction phase, an increase both of DBP and rTFH is observed.

The hydrolase activity ( $p$ NPP test system) was also measured in the cytoplasm before the induction and at the end of the HCDC. While no activity was found prior to induction, a surprisingly high intracellular

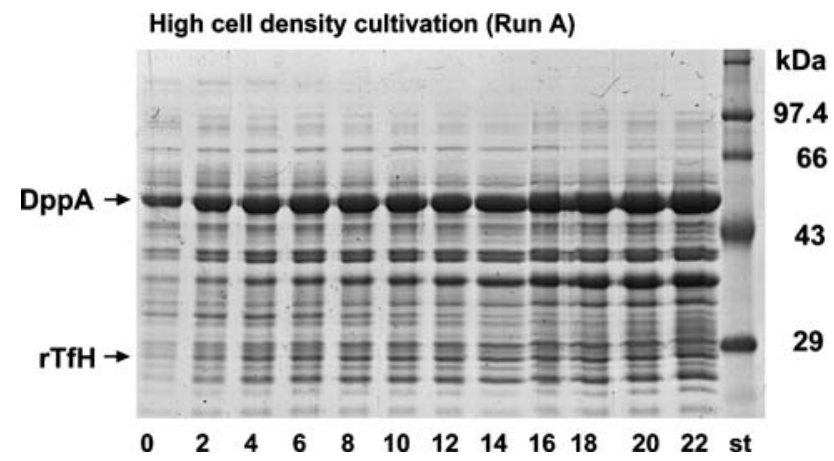

Fig. 8 SDS-PAGE: EFs of different cultivations are shown after increasing the temperature to $39^{\circ} \mathrm{C}$ to induce $\mathrm{rTfH}$ production, HCDC (Run A) activity was detected at the end of the cultivation process. Indeed, about two-thirds of the entire rTfH activity was located in the cytoplasm, apparently in soluble and active form. Any significant inclusion-body formation was not observed. The operational parameters and the results received in the two HCDC runs shown in Fig. 5 are summarized in Table 2. In spite of the different feed rates and the total induction times, the rTfH activities found in the different compartments are in reasonable agreement. The constant feed rate after induction in Run A yields higher specific activities obviously due to lower biomass formation. However, as a result of the long induction time, the productivity is lower for Run A than for Run B. In comparison to the batch runs (Table 1) the accumulation of product in the periplasm and cytoplasm is most noticeable. Thus the total volumetric activity is about 30 -fold larger than that achieved in the batch runs. These higher overall product concentrations are advantageously for rTfH recovery and purification.

Table 2 Applied operation parameters and achieved rTfH activities in fed-batch runs (starting glucose concentration $24 \mathrm{~g} \mathrm{~L}^{-1}, \mathrm{pH} 7, T=30^{\circ} \mathrm{C}, T_{\text {ind }}=39^{\circ} \mathrm{C}$ )

\begin{tabular}{|c|c|c|}
\hline Cultivation & Run A & Run B \\
\hline $\begin{array}{l}\text { DCW at induction } \\
\left(\mathrm{g} \mathrm{L}^{-1}\right)\end{array}$ & 38.5 & 42 \\
\hline Feed rate & $\begin{array}{l}\text { Constant } \\
\qquad\left(12.8 \mathrm{~g}_{\mathrm{glc}} \mathrm{h}^{-1}\right)\end{array}$ & $\begin{array}{l}\text { Exponential } \\
\qquad\left(\mu=0.12 \mathrm{~h}^{-1}\right)\end{array}$ \\
\hline $\begin{array}{l}\text { Estimated mean growth rate } \\
\text { after induction }\left(\mathrm{h}^{-1}\right)\end{array}$ & 0.03 & 0.07 \\
\hline Total induction time $(\mathrm{h})$ & 22.4 & 11.4 \\
\hline Final DCW $\left(\mathrm{g} \mathrm{L}^{-1}\right)$ & 53.2 & 67.8 \\
\hline \multicolumn{3}{|l|}{ Supernatant } \\
\hline $\begin{array}{l}\text { Volumetric activity } \\
\qquad\left(10^{3} \mathrm{U} \mathrm{L}^{-1}\right)\end{array}$ & 12.04 & 5.16 \\
\hline $\begin{array}{l}\text { Specific activity } \\
\left(10^{3} \mathrm{U} \mathrm{g}_{\mathrm{DCW}}^{-1}\right)\end{array}$ & 0.227 & 0.076 \\
\hline \multicolumn{3}{|l|}{ Periplasm } \\
\hline $\begin{array}{l}\text { Volumetric activity } \\
\qquad\left(10^{3} \mathrm{U} \mathrm{L}^{-1}\right)\end{array}$ & 74.22 & 51.69 \\
\hline $\begin{array}{l}\text { Specific activity } \\
\left(10^{3} \mathrm{U} \mathrm{g}_{\mathrm{DCW}}^{-1}\right)\end{array}$ & 1.395 & 0.762 \\
\hline \multicolumn{3}{|l|}{ Cytoplasm (soluble) } \\
\hline $\begin{array}{l}\text { Volumetric activity } \\
\qquad\left(10^{3} \mathrm{U} \mathrm{L}^{-1}\right)\end{array}$ & 141.24 & 156.74 \\
\hline $\begin{array}{l}\text { Specific activity } \\
\left(10^{3} \mathrm{U} \mathrm{g}_{\mathrm{DCW}}^{-1}\right)\end{array}$ & 2.655 & 2.312 \\
\hline \multicolumn{3}{|l|}{ Total } \\
\hline $\begin{array}{l}\text { Volumetric activity } \\
\qquad\left(10^{3} \mathrm{U} \mathrm{L}^{-1}\right)\end{array}$ & 227.5 & 213.59 \\
\hline $\begin{array}{l}\text { Specific activity } \\
\left(10^{3} \mathrm{U} \mathrm{g}_{\mathrm{DCW}}^{-1}\right)\end{array}$ & 4.28 & 3.15 \\
\hline $\begin{array}{l}\text { Productivity [U } \\
\left.\qquad\left(10^{3} \mathrm{gDCW} \mathrm{h}\right)^{-1}\right]^{\mathrm{a}}\end{array}$ & 0.19 & 0.28 \\
\hline
\end{tabular}

${ }^{\text {a Total induction time }}$ 


\section{Purification}

Two different strategies were applied to purify rTfH with regard to different uses. To gain $\mathrm{rTfH}$ with a high purification grade, the $\mathrm{His}_{6}$-affinity tag cloned at the Cterminal end of the bta 1 gene allowed a simple and effective chromatographic procedure. $\mathrm{rTfH}$ was purified from the culture broth or the periplasm, which was obtained by an osmotic shock treatment (Localization of rTfH section). In the following, the purification of rTfH is described, which originated from the periplasmic space. About $37 \mathrm{~g}$ of wet biomass (corresponding to ca. $6.5 \mathrm{~g}_{\mathrm{DCW}}$ ) was subjected to osmotic shock treatment $(1 \mathrm{~L}$ scale). After separating the cells by centrifugation, $25 \mathrm{~mL} \mathrm{Ni}^{2+}$ activated sepharose was directly added to the supernatant harbouring the periplasmic protein. After $1 \mathrm{~h}$ incubation, only low amounts of rTfH activity $(0.1 \%)$ could be detected in the supernatant. The suspension was then filled into a glass column. Particle settling could be improved by connecting a peristaltic pump to the column outlet. After connecting the column to a FPLC system, rTfH was washed with bindung buffer; rTfH was eluted by applying a linear gradient of imidazole (Fig. 9a). rTfH elution was observed at an imidazole concentration of about $200 \mathrm{mM}$. In the pooled fractions, a rTfH activity of $6.53 \mathrm{U} \mathrm{mL}^{-1}$ could be detected. The $\mathrm{His}_{6}$-affinity step resulted in a 29-fold purification and a loss of about $30 \%$ rTfH activity.

To further eliminate impurities and to remove high concentrations of $\mathrm{NaCl}$ and imidazole from the protein sample, gelfiltration was done using a Hi Load 26/60 Superdex 75 prep grade column with a $0.9 \% \mathrm{NaCl}$ buffer (Fig. 9b). Before applying the sample to the column, pooled fractions with rTfH from the $\mathrm{Ni}^{2+}$ affinity chromatography were concentrated by ultrafiltration (concentration factor 7; cut-off $10 \mathrm{kDa}$ ). Gelfiltration assured purification to homogeneity as shown by SDS-PAGE (Fig. 10) although only a minor increase of the specific activity was observed (Table 3 ). Gel filtration resulted in a further loss of $\mathrm{rTfH}$ activity of about $10 \%$. Totally, rTfH could be purified 30 -fold with a $57 \%$ recovery in activity by the applied purification route. Table 3 gives an overview of the procedure to obtain the highly purified $\mathrm{rTfH}$, which will be used for mechanistic studies (adsorption, kinetic) and structural analysis.

Contrary to the purification profile of the TfH from the culture broth of $T$. fusca cultivations, the overall yield could be increased from 14 to 57\% [7]. Prior to performing the first purification step, the supernatant containing TfH had to be concentrated by ammonium sulphate precipitation. By this method, a final recovery
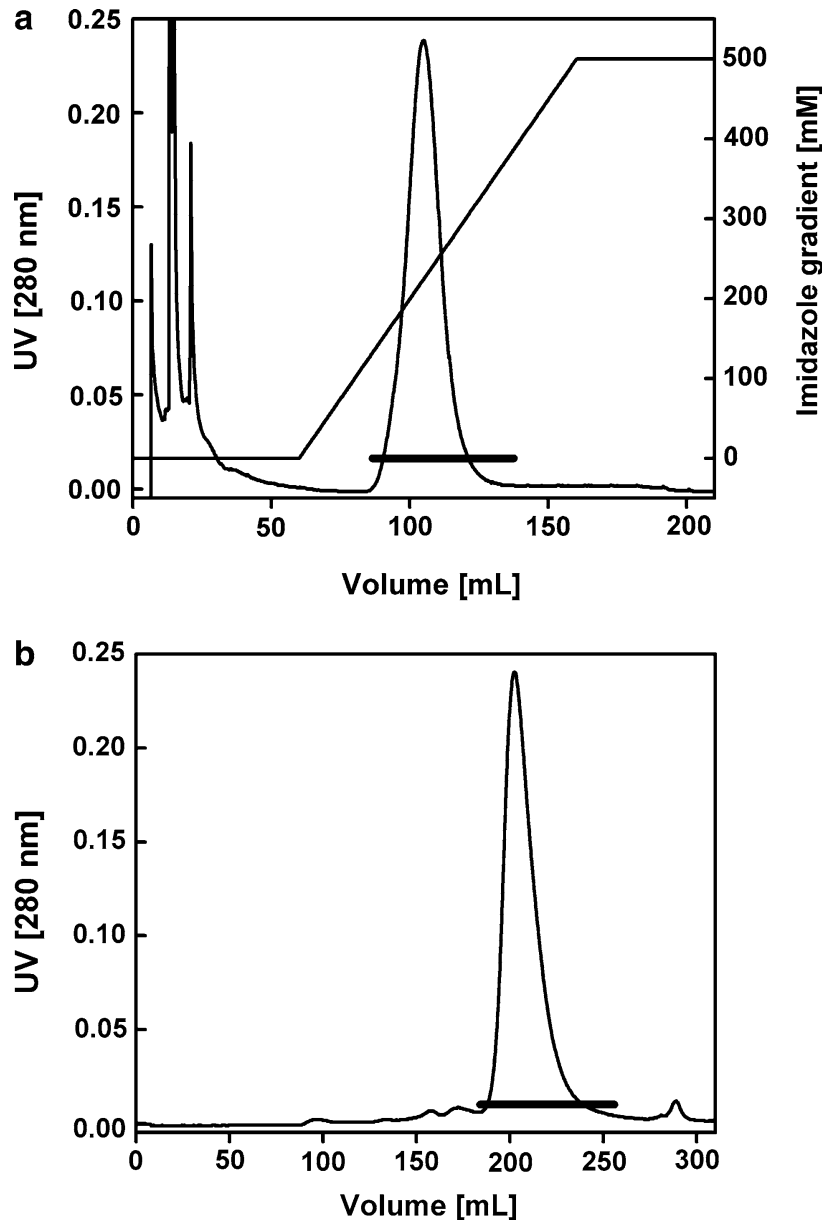

Fig. 9 Purification of rTfH from the PF. E. coli TG1 cells derived from a fed-batch cultivation (Run A); $37 \mathrm{~g}$ biomass was used for osmotic shock treatment, $\mathbf{a ~} \mathrm{Ni}^{2+}$-affinity chromatography with Chelating Sepharose Fast Flow, b gelfiltration with Superdex 75 prep grade; pooled fraction are marked by a line

of only $37 \%$ could be achieved because of the limited amounts of the precipitated proteins that could be redissolved [7]. By inserting the $\mathrm{His}_{6}$-affinity tag at the C-terminal end of $\mathrm{rTfH}$, precipitation could be avoided and the recombinant enzyme could be easily obtained from E. coli-culture broths independently of its composition.

For industrial processes, purification with $\mathrm{Ni}^{2+}$ affinity chromatography is too costly of course. Therefore, an alternative purification route was developed, which aimed at a rTfH preparation of a low purification grade but sufficient activity and stability for larger-scale investigations on polyester degradation. Activity test of the soluble protein in the cytoplasm obtained during HCDC showed that most of the expressed rTfH was not secreted into the periplasm but remained in the cytoplasm. Hence, the cells were disrupted by ultrasonification to get rTfH both from the 


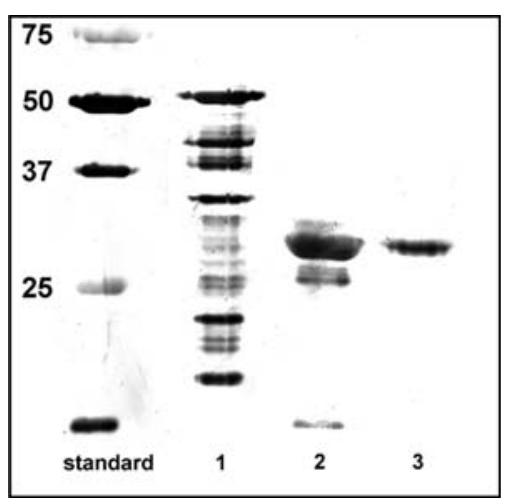

Fig. 10 SDS-PAGE: rTfH at different purification steps (silver staining), $37 \mathrm{~g}$ biomass was used for the osmotic shock treatment, cells derived from HCDC (Run A) standard: molecular mass protein standard, 1 supernatant from the periplasm, $2 \mathrm{Ni}^{2+}$. affinity chromatography, 3 pooled fraction after Superdex 75 gel chromatography

cytoplasm and the periplasm. In preliminary experiments, different ultrasonication conditions were tested. Three-fold pulses of $30 \mathrm{~s}$ each with 2 min break were found as the best treatment for the test conditions of $75 \mathrm{mg}$ biomass resuspended in $2 \mathrm{~mL}$ PBS buffer. Here, biomass from the HCDC Run B was used. After the separation of cell debris by centrifugation, an activity of $26.52 \mathrm{U} \mathrm{mL}^{-1}$ was detected corresponding to a specific activity of $4.1 \mathrm{U} \mathrm{g}_{\mathrm{DCW}}^{-1}$. Chemical disruption of the cells by a detergent formulation (BugBuster, see Localization of rTfH section) resulted only in a specific activity of $3.07 \mathrm{U} \mathrm{g}_{\mathrm{DCW}}^{-1}$ implying that cell disruption is more effective than the chemical treatment. Protein concentration of the crude extract was $2.57 \mathrm{mg} \mathrm{mL}^{-1}$. Taking the specific activity of the high-grade rTfH into account (445 $\mathrm{U} \mathrm{mg}_{\text {Protein }}^{-1}$ ), $1 \mathrm{mg}$ protein harboured $2.3 \%$ heterologous produced $\mathrm{rTfH}$. Because $\mathrm{rTfH}$ is very stable against higher temperatures [7], heat treatment was carried out at $55^{\circ} \mathrm{C}$ for $10 \mathrm{~min}$. Two routes were tested, namely either heat treatment of the disrupted cells immediately after the ultrasonication or heat treatment after the separation of the cell debris. Activity tests revealed that a heat treatment directly after the cell disruption yielded the best results. Thus the purification factor could be increased from 1.5 to 2 and a higher yield was observed. Table 3 summarized the results in detail.

\section{Discussion}

The recombinant strain E. coli TG1 harbouring the plasmid pCYTEXP1-OmpA-bta1-His 6 proved to be an appropriate system for expression, secretion and purification of the hydrolase from $T$. fusca. In comparison to cultivations with $T$. fusca and induction of $\mathrm{TfH}$ by adding polyesters a 1.5-2-fold higher volumetric activity could be obtained in batch cultivations of the recombinant E. coli strain. The volumetric activity could be further improved in fed-batch cultivations with glucose limitation. Considering only the extracellular and PFs, the increase is 20-fold. If one also accounts for the activity found in the cytoplasm, the total volumetric activity is over 50 -fold higher than that obtained from $T$. fusca. The overall volumetric productivity $\left[\mathrm{U}(\mathrm{L} \mathrm{h})^{-1}\right]$ increased by a factor more than 100 . Hence, the production of rTfH in recombinant $E$. coli is an attractive and promising approach for providing hydrolytic activity for polyester cleavage in degradation and recycling processes. This view is supported by the simple recovery route to give a crude and stable rTfH preparation, which did not exhibit activity losses after storage at $-20^{\circ} \mathrm{C}$ for several weeks.

A further improvement of rTfH production in $E$. coli is the insertion of the $\mathrm{His}_{6}$ tag at the C-terminal end of the enzyme. Purification of the wild-type TfH proved to be quite ineffective. A three-step purification strategy (precipitation, ion-exchange chromatography and hydrophobic interaction chromatography) resulted in only $14 \%$ yield in activity [7]. With the $\mathrm{His}_{6}$ tag, $57 \%$ activity yield of rTfH could be obtained in a two-step purification route starting from the supernatant and PFs. A 30-fold purification was achieved yielding a specific activity of $445 \mathrm{U} \mathrm{mg}^{-1}$. From this value, the overall concentration of the produced $\mathrm{rTfH}$ can be estimated as about $0.5 \mathrm{~g} \mathrm{~L}^{-1}$.

In the batch runs with LB and the defined medium, better results were found by induction to only $39^{\circ} \mathrm{C}$. Therefore, fed-batch cultivations were carried out with this induction temperature. While both the media yielded comparable volumetric activities, the specific activities differ significantly (about fivefold in LB). LB medium obviously supplies $E$. coli with all nutrients to easily synthesize the recombinant protein at high specific productivity and to secrete it across the cell envelope. Increased growth rates and facilitated protein production in LB medium are frequently reported in the literature [22, 23]. In batch cultivations with both media, rTfH expression as well as its transport across the cell membrane in the periplasm and the subsequent release into the cultivation media are seemingly coupled with growth and $\mathrm{CO}_{2}$ generation (Figs. 1, 2).

In the fed-batch cultivations with the defined medium, roughly tenfold higher activities could be achieved in the supernatant and periplasm than in batch operation. Surprisingly, the specific activities in the glucose limited fed-batch process are even twofold higher. If one accounts for the soluble cytosolic fraction 
Table 3 Summary of two routes used to recover and purify rTfH from HCDC; the highly purified product was obtained from the periplasmic fraction (Run A), the low grade product was recovered from the cytoplasm and periplasm by ultrasonification (Run B)

\begin{tabular}{|c|c|c|c|c|c|}
\hline Purification step & $\begin{array}{l}\text { Total units } \\
\left(10^{3} \mathrm{U} \mathrm{L}^{-1}\right)\end{array}$ & $\begin{array}{l}\text { Total protein } \\
\left(\mathrm{mg} \mathrm{L}^{-1}\right)\end{array}$ & $\begin{array}{l}\text { Specific activity } \\
\left(\mathrm{U} \mathrm{mg}^{-1}\right)\end{array}$ & Purification-factor & Yield (\%) \\
\hline \multicolumn{6}{|l|}{ High grade rTfH } \\
\hline Supernatant with periplasmic protein & 8.57 & 587 & 15 & 1 & 100 \\
\hline $\mathrm{Ni}^{2+}$-affinity chromatography & 6.53 & 15 & 436 & 29 & 71 \\
\hline Gel filtration & 4.89 & 11 & 445 & 30 & 57 \\
\hline \multicolumn{6}{|l|}{ Low grade rTfH } \\
\hline Crude extract & 26.52 & 2,570 & 10.32 & 1 & 100 \\
\hline Heat treatment & 22.51 & 1,470 & 15.3 & 1.5 & 85 \\
\hline Ultrasonification + heat treatment & 28.89 & 1,410 & 20.5 & 2 & $109^{\mathrm{a}}$ \\
\hline
\end{tabular}

${ }^{a}$ Crude extract (ultrasonification plus centrifugation)

the activity yields further improve remarkably. The total specific activity of the HCDCs is in the same range as those obtained for the batch process with LB medium. An influence of the $\mathrm{His}_{6}$ tag and the full or truncated OmpA leader sequence on $\mathrm{TfH}$ activity can hardly be estimated from the results of this study. However, the high activities of rTfH obtained suggest that small sequences at the $\mathrm{C}$ - and $\mathrm{N}$ - terminals might have little effect on TfH activity. The fraction of soluble active protein located in the cytoplasm is remarkably high but its amount can be estimated to be less than $2 \%$ of the total protein content of the cells (assuming $50 \%$ protein of DCW). Therefore, it is understood that inclusion body formation could not be detected.

Among the different mechanisms to transport protein from the cytoplasm across the cell membrane to the periplasm, the Sec pathway is the most prominent for prokaryotic organisms [24]. The Sec-translocation process is thought to be generally responsible for the transport of newly synthesized but unfolded proteins out of the cytosol to the periplasm. This process is accompanied by the cleavage of the leader sequence (OmpA) from the pre-protein and proper folding in the periplasm. If we assume that the Sec pathway is also active for the transport of the heterologous rTfH out of the cytoplasm, it is obvious that due to its accumulation in the cytoplasm during the fed-batch runs, the translocation rate is less than the expression rate. Hence, transport into the periplasm apparently presents a limiting step. It might be possible that the entire translocation process is subjected to an equilibrium phenomenon in as far as high protein concentrations in the periplasm reduces the transport rate. This is evident if the $\mathrm{rTfH}$ masses (or units) in periplasm and cytoplasm are not referred to cultivation volume as given in Table 2 but to their respective actual volumes. If it is assumed that the volume of periplasm is about $5 \%$ of the cell volume then the rTfH concentration in the periplasm is more than tenfold higher than in the cytoplasm. This might explain that no cytoplasmic rTfH activity was found in the batch runs, where the periplasmic protein was entirely released in the extracellular space. In contrast, relatively little protein was transported across the outer cell wall into the medium in the fed-batch runs with high cell densities and higher rTfH activities were found in both the cytoplasm and periplasm.

As to the Sec pathway, the rTfH in the cytoplasm should be unfolded and hence is not expected to be in the active form. However, when gaining the cytoplasmic fraction (see Localization of rTfH section) immediate activity was observed. This suggests that either folding takes place spontaneously in the PBS buffer or the cytosol already harbours the active folded rTfH and its translocation follows another mechanism. Unfortunately, our study does not allow to distinguish between the two possibilities.

Though it is often assumed that E. coli laboratory strains do not secrete proteins across the cell envelope in the extracellular medium at normal growth conditions [25], leakage of the outer cell membrane is a common phenomenon observed for a variety of cultivation conditions as reported in recent papers $[20,25,26]$ and review articles [21,27]. Permeability of the outer cell wall may depend on medium composition, growth rates, cell concentration, changes in cultivation conditions, etc. For instance, $\mathrm{Mg}^{2+}$ and $\mathrm{Ca}^{2+}$ increase leakage of the outer membrane [28]. Rise of temperature causes changes in membrane permeability and fluidity due to alterations in the lipid composition of the cell wall. This aspect was particularly studied in continuous cultures of E. coli [26] and an increased permeability was found at higher growth rates. Rinas and Hoffmann [20] studied in detail the leakage of host-cell proteins during HCDCs of recombinant and non-recombinant $E$. coli. These authors reported that the proteins found extracellularly are of 
periplasmic origin except the heat-shock protein DnaK. Various and interrelated stress factors in the temperature-induced HCDC are suggested to be responsible for the migration of periplasmic proteins in the extracellular medium.

In all cultivations performed in this study, $\mathrm{rTfH}$ could be detected in the medium without applying any additional measures to permeabilize the outer cell membrane. Cell lysis as a possible mechanism of rTfH release can be excluded as the cleavage of the OmpA sequence in the extracellularly found hydrolase indicates transport across the cytoplasmic membrane by the Sec-translocation mechanism. Any significant cell lysis would also release cytoplasmic rTfH still containing the complete signal sequence.

In batch cultivations (Figs. 1,2) with LB and the defined medium, induction of rTfH expression was started at low cell densities. Immediately after the temperature upshift, rTfH appeared in the periplasm but its periplasmic activity passes a maximal value just in the first part of the exponential growth phase. In accordance with the findings of Shokri et al. [26], the migration of the periplasmic $\mathrm{rTfH}$ in the medium is obviously growth coupled. This effect may be attributed to changes in cell-wall composition which facilitate transport into the extracellular medium. On the other hand, during cell growth and cell-wall biosynthesis, transient openings of the outer membrane and the murein layer are unavoidable [29], thus the protein of periplasmic origin can migrate into the extracellular medium. Furthermore, vesiculation and fragmentation of the outer membrane may occur as a natural phenomenon during the exponential growth phase $[30,31]$ which is thought to be caused by an imbalance of the outer-membrane biogenesis and peptidoglucan synthesis. Therefore, several growth-coupled phenomena may contribute to the migration of periplasmic proteins in the medium.

At the end of the batch cultivations, the produced rTfH has entirely accumulated in the medium. As can be discerned from the SDS-PAGE shown in Fig. 3 the transport of rTfH across the cell envelope is accompanied simultaneously by release of other periplasmic proteins [20]. The kinetics of rTfH accumulation in the extracellular medium (Figs. 1,2) agrees qualitatively with the results shown in Fig. 3, particularly, no significant migration is observed at low growth rates after the induction when the culture adapts to the higher temperature. Rinas and Hoffmann [20] found DBP as the most prominent periplasmic protein transported to the medium. This observation and even the release kinetics reported by these authors for high cell-density conditions are in striking agreement with our findings for batch conditions (relatively low cell densities) as observed in the defined medium (Fig. 3b).

In contrast to the batch runs, rTfH accumulates in the cytoplasm and periplasm during the glucoselimited fed-batch cultivations after induction at higher cell densities. The relative fractions of $\mathrm{rTfH}$ released extracellularly is low. For an induction period of $11 \mathrm{~h}$, only 5 and $10 \%$ of the PF are released for Run A and $\mathrm{B}$, respectively. As in Run $\mathrm{B}$, the growth rate was higher as a result of exponential glucose feeding; this finding underpins the view that the permeability of the outer membrane is related to growth rate. As shown in Fig. 8 the outer membrane is already leaky before the temperature shift from 30 to $39^{\circ} \mathrm{C}$ as among other periplasmic proteins the DBP is predominantly found in the extracellular medium as reported previously [20]. Of course, in the induction phase a further increase of DBP is observed (Fig. 8). Though the transport of rTfH in the periplasm as well as its migration into the extracellular medium continued (Fig. 7), the cultivation was terminated to prevent cell lysis after growth ceased. However, in the non-growth phase, glucose does not accumulate in the medium but is consumed as is also exhibited by the monotonous increase of $\mathrm{CO}_{2}$ generation. This points to the increased maintenance and ATP demand for translocation of the heterologous gene product ( $\mathrm{rTfH})$ across the inner cell membrane.

These mechanisms, which govern the local distribution of rTfH are not yet understood. Though cellspecific productivities are in a comparable range, product distributions differ largely. Our results suggest that the outer membrane permeability is related with the growth rate and hence all rTfH can migrate into the extracellular medium at high growth rates (batch runs). Therefore, final product release across the cell envelope could play an important role in the overall translocation process as product accumulation in the periplasm seemingly reduces the translocation rate from the cytoplasm by the Sec pathway. This hypothesis requires further investigations, which are presently in preparation. Therefrom, new strategies for cultivation and downstream processing with improved product qualities are expected.

Acknowledgments Support of this work by Deutsche Forschungsgemeinschaft is gratefully acknowledged. Thanks are due to Rita Getzlaff for analysis of protein sequences.

\section{References}

1. Tokiwa Y, Suzuki T (1977) Hydrolysis of polyesters by lipases. Nature 270:76-78 
2. Witt U, Müller RJ, Deckwer WD (1996) Biodegradable polyester and material made therefrom. Germany WO9607687

3. Müller RJ, Kleeberg I, Deckwer WD (2001) Biodegradation of polyesters containing aromatic constituents. J Biotechnol 86:87-95

4. Witt U, Müller RJ, Deckwer WD (1997) Biodegradation behavior and material properties of aliphatic-aromatic polyesters of commercial importance. J Environ Polym Degrad 5:81-89

5. Kleeberg I, Hetz C, Kroppenstedt RM, Müller RJ, Deckwer WD (1998) Biodegradation of aliphatic-aromatic copolyesters by Thermomonospora fusca and other thermophilic compost isolates. Appl Environ Microbiol 64:1731-1735

6. Deckwer WD, Müller RJ, van den Heuvel J, Kleeberg I, WIDOW U (2001) DNA-Sequenzen, die Estergruppen spaltende Enzyme kodieren. Germany DE10030529A1

7. Kleeberg I, Welzel K, van den Heuvel J, Müller RJ, Deckwer WD (2005) Characterization of a new extracellular hydrolase from Thermobifida fusca degrading aliphaticaromatic copolyesters. Biomacromolecules 6:262-270

8. Gouda MK, Kleeberg I, van den Heuvel J, Müller RJ, Deckwer WD (2002) Production of a polyester degrading extracellular hydrolase from Thermomonospora fusca. Biotechnol Prog 18:927-934

9. Müller RJ, Schrader H, Profe J, Dresler K, Deckwer WD (2005) Enzymatic degradation of poly(ethylene terephthalate): rapid hydrolyse using a hydrolase from $T$. fusca. Macromol Rapid Commun 26:1400-1405

10. Carter P, Bedouelle H, Winter G (1985) Improved oligonucleotide site-directed mutagenesis using M13 vectors. Nucleic Acids Res 13:4431-4443

11. Sambrook J, Russell D (2001) Molecular cloning, a laboratory manual, 3rd edn. Cold Spring Harbor Laboratory Press, New York

12. Korz DJ, Rinas U, Hellmuth K, Sanders EA, Deckwer WD (1995) Simple fed-batch technique for high cell density cultivation of Escherichia coli. J Biotechnol 39:59-65

13. Yamane T, Shimizu S (1984) Fed-batch techniques in microbiol processes. In: Scheper $\mathrm{T}$ (ed) Advances in biochemical engineering and biotechnology. Springer, Berlin Heidelberg New York, pp 145-194

14. Heukeshoven J, Dernick R (1988) Improved silver staining procedure for fast staining in PhastSystem Development Unit. I. Staining of sodium dodecyl sulfate gels. Electrophoresis 9:28-32

15. Schmidt-Dannert C, Sztajer H, Stocklein W, Menge U, Schmid RD (1994) Screening, purification and properties of a thermophilic lipase from Bacillus thermocatenulatus. Biochim Biophys Acta 1214:43-53
16. Neu HC, Heppel LA (1965) The release of enzymes from Escherichia coli by osmotic shock and during the formation of spheroplasts. J Biol Chem 240:3685-3692

17. Gottschalk K (1986) Bacterial metabolism, 2nd edn. Springer, Berlin Heidelberg New York

18. Korz DJ (1993) Entwicklung von Prozeßstrategien zur Kultivierung von Escherichia coli zu hohen Zelldichten. Technical University of Munich, Munich

19. Abouhamad WN, Manson M, Gibson MM, Higgins CF (1991) Peptide transport and chemotaxis in Escherichia coli and Salmonella typhimurium: characterization of the dipeptide permease (Dpp) and the dipeptide-binding protein. Mol Microbiol 5:1035-1047

20. Rinas U, Hoffmann F (2004) Selective leakage of host-cell proteins during high-cell-density cultivation of recombinant and non-recombinant Escherichia coli. Biotechnol Prog 20:679-687

21. Choi JH, Lee SY (2004) Secretory and extracellular production of recombinant proteins using Escherichia coli. Appl Microbiol Biotechnol 64:625-635

22. Broedel SH, Papciak SM, Jones WR (2001) The selection of optimum media formulations for improved expression of recombinant proteins in E. coli, vol 2. Athena Enzyme Systems Technical Bulletin

23. Rothen SA, Sauer M, Sonnleitner B, Witholt B (1998) Growth characteristics of Escherichia coli HB101 [pGEc47] on defined medium. Biotechnol Bioeng 58:92-100

24. Mori H, Ito K (2001) The Sec protein-translocation pathway. Trends Microbiol 9:494-500

25. Zhang G, Brokx S, Weiner JH (2006) Extracellular accumulation of recombinant proteins fused to the carrier protein YebF in Escherichia coli. Nat Biotechnol 24:100-104

26. Shokri A, Sanden AM, Larsson G (2002) Growth ratedependent changes in Escherichia coli membrane structure and protein leakage. Appl Microbiol Biotechnol 58:386-392

27. Shokri A, Sanden AM, Larsson G (2003) Cell and process design for targeting of recombinant protein into the culture medium of Escherichia coli. Appl Microbiol Biotechnol 60:654-664

28. Vaara M (1992) Agents that increase the permeability of the outer membrane. Microbiol Rev 56:395-411

29. Neidhardt FC, Ingraham JL, Schaechter M (1990) Physiology of the bacterial cell: a molecular approach. Sinauer Associates, Sunderland

30. Hoekstra D, Van Der Laan JW, De Leij L, Witholt B (1976) Release of outer membrane fragments from normally growing Escherichia coli. Biochim Biophys Acta 455:889-899

31. Wensink J, Witholt B (1981) Outer-membrane vesicles released by normally growing Escherichia coli contain very little lipoprotein. Eur J Biochem 116:331-335 